\title{
Review
}

\section{Penetrating cardiac injuries: literature review and analysis of the forensic approach}

\author{
Michela Ferrara ${ }^{1}$, Benedetta Baldari ${ }^{2}$, Simona Vittorio ${ }^{2}$, Giuseppe Bertozzi ${ }^{1}$, \\ Luigi Cipolloni $^{1, *}$, Stefania De Simone ${ }^{1}$ \\ ${ }^{1}$ Department of Clinical and Experimental Medicine, Section of Legal Medicine, University of Foggia, 71122 Foggia, Italy \\ ${ }^{2}$ Department of Anatomical, Histological, Forensic and Orthopedic Sciences, Sapienza University of Rome, 00185 Rome, Italy \\ *Correspondence: luigi.cipolloni@unifg.it (Luigi Cipolloni) \\ Academic Editor: Graham Pawelec \\ Submitted: 27 August 2021 Revised: 13 December 2021 Accepted: 15 December 2021 Published: 18 January 2022
}

\begin{abstract}
Penetrating cardiac injuries represent an increasingly frequent type of trauma in clinical and autopsy practice. The present study aims to review the specialist literature of the last decade (2010-2020) to assess whether the main features of these lesions have changed compared to previous years. The following characteristics were considered: sex, age, cardiac structure involved, execution or not of surgery and postoperative survival, hemodynamic stability, circumstances and mechanism of production, injury and cause of death. Furthermore, the authors propose a practical appraisal of penetrating heart injury in which death was due to a delay in rescue. In line with the data obtained from the practical case, the review showed that compared to the past, the differences concern especially the mortality rate. This paper highlights that the forensic pathologist who approaches a case of transcardiac injury must consider that the circumstances of death are not always attributable to accidental events, attacks or suicides, but may also be due to clinical malpractice or failure to rescue.
\end{abstract}

Keywords: Penetrating heart wounds; Transcardiac injuries; Duty to rescue

\section{Introduction}

Penetrating heart wounds refer to all traumatic cardiac injuries secondary to penetrating action. This kind of trauma is frequently observed in the clinical setting and even more in the autopsy practice, as the injuries are often lethal $[1,2]$. According to the literature, the leading causes of penetrating cardiac trauma are stab wounds and gunshot wounds, succeeded by accidental impalements [3].

Patients with a penetrating cardiac wound may present varying clinical conditions, ranging from complete hemodynamic stability to cardiac arrest. Physicians must make the diagnosis quickly and promptly start the treatment to reduce mortality [4].

The outcomes of these kind of lesions depend on multiple factors, including mechanism of injury, cardiac site involved, the extent of the damage, hemodynamic stability, the time elapsed since the production of the injury to the diagnosis, and implementation of adequate therapy [4]. Other survival factors are the need for cardiopulmonary resuscitation (CPR) during first aid, cardiovascular-respiratory trauma (CVRS) score at hospitalization, and damage to large intra-pericardial vessels [1].

Pereira et al. [4] found that there has been lower mortality associated with cardiac trauma in recent years, likely due to advances in pre-hospital treatment in local emergency services and shorter transfer times. Therefore, the patient often arrives at the emergency room in an optimal physiological state to receive timely treatment [5]. The long-term outcomes of patients with penetrating heart wounds who have not presented coronary or valvular lesions and who pass the acute phase are optimal, with minimal cardiac morbidity related to the lesion suffered [6].

The present study aims to review the literature on penetrating heart wounds over the past decade (2010 to 2020) to develop a systematic approach to assessing this kind of injury. Studying the progress of diagnostic and therapeutic knowledge of these wounds is essential to clarify all the questions that such cases could have in the forensic field.

\section{Materials and methods}

Information Sources and Search: For this literature review, PubMed database was questioned. A primary selection was conducted with a search strategy, using the keywords "penetrating cardiac injury" and "transcardiac injury".

Study Selection and Data Collection Processes: After the initial literature searches conducted, the case reports were selected after the evaluation of the title and abstract, and then potentially relevant case reports were further assessed for eligibility. Full-length articles were preferred; duplicate manuscripts or only-abstract-available texts were excluded.

Eligibility: All case reports in which patients were classified in terms of sex, age, involved cardiac structure, execution or not of surgery and post-operative survival, hemodynamic stability, circumstances and mechanism of production the injury and cause of death in case of decease was selected. Inclusion criteria were: publication date from 
1 January 2010 to 31 December 2020; English language. Moreover, the references of the selected articles were also reviewed. Eclusion criteria were: object migration from other locations [7-9], iatrogenic cardiac trauma caused by medical devices or diagnostic procedures [10-12], cardiac injury following road-chest trauma, non penetrating trauma $[13,14]$, unrelated events [15], trauma years before [16], aortic pathologies [17].

Results: Following these procedures, 49 case reports were included in the present review.

To validate the effectiveness of the therapeutic improvements in pre-hospital and local emergency service settings, above all related to shorter transfer times, the authors examined a concrete case in which timing of first aid was delayed with unexpected death of the patient.

A 20-years old male was accidentally shot. The accidentally shooter tried to hide what happened, referred to the authorities a minor injury during a joke. The ambulance service arrived about an hour after the accident, and the patient arrived at the emergency room an hour and more than a half later. Pupillary reflexes were present, as were dyspnoea, tachycardia, sweating, and hypotension. Physical examination revealed the presence of a gunshot wound on the right arm without an exit hole. So the physician alerted the helicopter rescue to transport the boy to the nearest surgery center. The death occurred about three and a half hours after the first ambulance call.

\section{Results}

The results of the literature review are summarized in Table 1 (Ref. [6,18-63]).

\subsection{Gender}

Of the 49 cases analyzed (mean age 32.13 ), forty victims were men (mean age 28.1), and nine victims were women (mean age 38.97).

\subsection{Damaged cardiac structure}

In fourteen cases $(30 \%)$, the damage concerned the right ventricle, in nine patients $(18.3 \%)$, the left ventricle, and in four cases $(8.1 \%)$ both ventricles. In five cases $(10.2 \%)$, the lesion involved the right ventricle and the interventricular septum. In three patients $(6.1 \%)$, the damage affected both the interventricular septum and the left ventricle. In two cases (4\%), the lesion involved the left anterior descending artery (LAD), while in another two patients, the pulmonary artery. In the remaining cases, the damage involved other cardiac structures, as summarized in Table 1.

\subsection{Survival and cause of death}

Six subjects $(12.2 \%)$ - five male and one female died, including four before being evaluated in the hospital. The leading cause of death was cardiac tamponade. Of the two patients who arrived at the hospital, one underwent surgery and died 14 days after the traumatic event due to respiratory failure resulting from acute respiratory distress syndrome. The other patient did not undergo surgery as there were no traumatic myocardial lesions without a diagnosis of LAD rupture. This misdiagnosis resulted in death within nine days of being injured. The cause of death was cardiac tamponade, in association with infarction of the interventricular septum and of the anterior wall of the left ventricle.

\subsection{Means of injury}

Based on the collected data, three main categories group the kind of weapons: sharp objects, projectiles, and pointed objects. In $44.9 \%$ of cases, the cardiac injury was due to sharp objects, consisting of knives (seven cases), scissors (one case), machete (one case), and circular saw (one case). In the remaining cases, the kind of weapon was unknown. In $44.9 \%$ of cases, the object used acted as a projectile. In detail: nail gun (eleven cases), firing bullets (five cases), air pellet gun (two cases), fragments propelled from a lawnmower (two cases), an arrow (two cases). In the remaining $10.2 \%$ of cases, pointed objects caused the lesions: a wooden stick (two cases), ice pick (one case), bodkin (one case), stingray barb (one case).

\subsection{Circumstances of production of the lesion}

Concerning the circumstances of the production of the injury, in $28.6 \%$ of cases, the event was accidental. In $16.4 \%$ of cases, the lesion resulted from an assault or a fight; in $14.2 \%$, there was a suicide attempt. In the remaining $40.9 \%$ of cases, the authors did not specify the scenario.

\section{Discussion}

As a result of the present literature review, the authors pointed out the following evaluations regarding the characteristics of penetrating cardiac lesions considered by this study and their evolution over the last ten years. Many patients in the analyzed clinical cases were young males, with a mean age of 32.13 years, similar to other studies [64].

The mortality rate in the present study is lower than the analysis previously published [4].

Unlike previous studies, where injuries were mainly caused by stab and gunshot, in the present case series, nail guns are the predominant weapons, followed by knives [65]. According to the literature, the most common causes of death were cardiac tamponade and hemorrhagic shock [66]. The most implicated cardiac structure was the right ventricle, followed by the left ventricle and multiple chamber lesions, in agreement with other studies; this is probably due to the greater exposure of the right heart chamber, considering the cardiac axis rotation [67]. In most cases, the circumstance of production of the injury was accidental, followed by assault and suicide attempt. 
Table 1. Qualitative and quantitative data resulted of the literature review.

\begin{tabular}{|c|c|c|c|c|c|c|c|}
\hline Case report & Sex & Age & Involved cardiac site & Surgery & Survival & Circumstances and mechanism & Cause of death \\
\hline Connelly et al. [6] & male & $26 \mathrm{y}$ & $\begin{array}{l}\text { anterior right ventricle, ventricular } \\
\text { sept, mitral valve }\end{array}$ & yes & Yes & altercation, knife & \\
\hline Kulaylat et al. [18] & female & $29 \mathrm{~m}$ & anterior right ventricle & yes, hemodinamicallystable & Yes & self-inflicted (accidental), pneumatic nail gun & \\
\hline Cottini et al. [19] & female & $38 \mathrm{y}$ & anterior left ventricle, ventricular sept & $\begin{array}{l}\text { yes, hemodinamically unstable, } \\
\text { cardiac tamponade }\end{array}$ & Yes & self-inflicted (suicide attempt), stab wound & \\
\hline Diez et al. [20] & male & $31 \mathrm{y}$ & both left and right ventricles & yes, cardiac tamponade & Yes & not specified, machete & \\
\hline Grande et al. [21] & male & $57 \mathrm{y}$ & anterior right ventricle & yes, hemodynamically stable & Yes & self-inflicted (suicide attempt), scissors & \\
\hline Haghshenas et al. [22] & male & $53 \mathrm{y}$ & right ventricle & yes & Yes & self-inflicted, nail gun & \\
\hline Leite et al. [23] & male & $18 \mathrm{y}$ & anterior right ventricle & yes, cardiac tamponade & Yes & fight, knife & \\
\hline Kremer et al. [24] & male & $22 \mathrm{y}$ & right ventricle & yes, hemodynamically stable & Yes & altercation, stabwound & \\
\hline Gatti et al. [25] & male & $28 \mathrm{y}$ & Left ventricle, ventricular sept & yes, cardiactamponade & Yes & notspecified, stabwound & \\
\hline Claassen et al. [26] & male & $20 \mathrm{y}$ & anterior right ventricle & yes & Yes & notspecified, knife & \\
\hline Claassen et al. [26] & male & $27 \mathrm{y}$ & pulmonic valve & $\begin{array}{l}\text { yes, hemodynamically unsta- } \\
\text { ble, cardiac tamponade }\end{array}$ & Yes & notspecified, stabwound & \\
\hline Krishna et al. [27] & male & $16 \mathrm{y}$ & Anteriorleftventricle & no & $\begin{array}{l}\text { no (dead on arrival at } \\
\text { the hospital) }\end{array}$ & assault, icepick & $\begin{array}{l}\text { cardiogenic shock as a re- } \\
\text { sult of cardiac tamponade }\end{array}$ \\
\hline Zhang et al. [28] & female & $4 y$ & anterior right ventricle & yes & Yes & self-inflicted (accidental), pneumatic nail gun & \\
\hline Hsia et al. [29] & female & $54 \mathrm{y}$ & right ventricle & yes, hemodynamically stable & Yes & accidental, woodenknittingneedle & \\
\hline Očko et al. [30] & male & $38 \mathrm{y}$ & left ventricle & no & no (dead on the scene) & self-inflicted (suicide attempt), crossbow & haemorrhagic shock \\
\hline Oliemy et al. [31] & male & $22 \mathrm{y}$ & atrial septum & yes & Yes & not specified, stab wound & \\
\hline Barbosa et al. [32] & male & $18 \mathrm{y}$ & right ventricle & yes & Yes & not specified, sharp weapon & \\
\hline Greenlees et al. [33] & male & $16 \mathrm{y}$ & atrial septum, apex of the left ventricle & yes, hemodynamically stable & Yes & accidental, air pellet gun & \\
\hline Karigyo et al. [34] & male & $23 \mathrm{y}$ & ventricular apex & yes, hemodynamically unstable & Yes & $\begin{array}{l}\text { accidental, shrapnel from the blade of a grass- } \\
\text { cutting tool }\end{array}$ & \\
\hline Pradhan et al. [35] & female & $56 y$ & right ventricle & yes, hemodynamically stable & Yes & accidental, impalement on a wooden stick & \\
\hline Yu et al. [36] & male & $42 \mathrm{y}$ & anterior and posterior left ventricle & yes, cardiac tamponade & Yes & not specified, stab wound & \\
\hline Enomoto et al. [37] & female & $66 y$ & $\begin{array}{l}\text { atrial septum, septal leaflet, right ven- } \\
\text { tricle, superior vena cava }\end{array}$ & yes & Yes & attack, stab wound & \\
\hline Gnassingbé et al. [38] & male & $10 \mathrm{y}$ & left ventricle & yes & Yes & attack, knife & \\
\hline
\end{tabular}


Table 1. Continued.

\begin{tabular}{|c|c|c|c|c|c|c|c|}
\hline Case report & Sex & Age & Involved cardiac site & Surgery & Survival & Circumstances and mechanism & Cause of death \\
\hline Han et al. [39] & male & $31 \mathrm{y}$ & $\begin{array}{l}\text { anterior and posterior mitral valve leaflets, } \\
\text { ventricular septum }\end{array}$ & $\begin{array}{l}\text { yes, hemodynam- } \\
\text { ically stable }\end{array}$ & Yes & not specified, stab wound & \\
\hline Branch et al. [40] & female & e $40 y$ & left ventricle & no & $\begin{array}{l}\text { no (dead at the hospital } 34 \\
\text { minutes from incident) }\end{array}$ & self-inflicted, shotgun & $\begin{array}{l}\text { hemopericardium and subsequent cardiac } \\
\text { tamponade }\end{array}$ \\
\hline Faloye et al. [41] & male & $34 \mathrm{y}$ & $\begin{array}{l}\text { anterior right ventricle, ventricular sept, } \\
\text { anterior leaflet of the tricuspid valve }\end{array}$ & yes & $\begin{array}{l}\text { no (dead at the hospital } 14 \\
\text { days from incident) }\end{array}$ & not specified, stab wound & respiratory failure \\
\hline Rupprecht et al. [42] & male & $18 \mathrm{y}$ & left ventricle & yes & Yes & accidental, nail gun & \\
\hline Işık et al. [43] & male & $11 \mathrm{y}$ & atrial septum, anterior right ventricle & $\begin{array}{l}\text { yes, hemodynam- } \\
\text { ically stable }\end{array}$ & Yes & not specified, air gun pellet & \\
\hline Kumar et al. [44] & male & $37 \mathrm{y}$ & junction of left atrium and pulmonary veins 1 & no & no (dead on the scene) & attack, bodkin & heart failure due to cardiac tamponade \\
\hline Chen et al. [45] & male & $32 \mathrm{y}$ & LAD coronary artery & yes & Yes & accidental, pneumatic nail gun & \\
\hline Maffei et al. [46] & male & 30 & lateral left ventricle, right ventricle & $\begin{array}{l}\text { yes, hemodynam- } \\
\text { ically stable }\end{array}$ & Yes & not specified, gunshot & \\
\hline Nwiloh et al. [47] & male & $11 \mathrm{y}$ & right ventricle, ventricular septum & yes & Yes & not specified, arrow & \\
\hline Duric et al. [48] & male & $45 \mathrm{y}$ & right ventricle & $\begin{array}{l}\text { yes, hemodynam- } \\
\text { ically stable }\end{array}$ & Yes & $\begin{array}{l}\text { self-inflicted (suicide attempt), } \\
\text { knife }\end{array}$ & \\
\hline Bartoloni et al. [49] & male & $29 y$ & LAD coronary artery & no & no (dead 9 days after injury) & attack, knife & $\begin{array}{l}\text { cardiac tamponade in patient with my- } \\
\text { ocardial infarction of interventricular sep- } \\
\text { tum and anterior wall of left ventricle }\end{array}$ \\
\hline Michalsen et al. [50] & male & $3 y$ & right ventricle, interventricular septum & yes & Yes & accidental, pneumatic nail gun & \\
\hline Michalsen et al. [50] & male & $37 \mathrm{y}$ & right ventricle, interventricular septum & $\begin{array}{l}\text { yes, hemodynam- } \\
\text { ically stable }\end{array}$ & Yes & self inflicted, pneumatic nail gun & \\
\hline Esfahani et al. [51] & male & $6 y$ & right atrium & yes & Yes & $\begin{array}{l}\text { accidental, projectile propelled by } \\
\text { a lawnmower }\end{array}$ & \\
\hline Madani et al. [52] & male & $17 \mathrm{y}$ & pulmonary artery & yes & Yes & accidental, nail gun & \\
\hline Jodati et al. [53] & male & $24 \mathrm{y}$ & $\begin{array}{l}\text { right ventricle, interventricular septum, an- } \\
\text { terior mitral leaflet }\end{array}$ & yes & Yes & accidental, pneumatic nail gun & \\
\hline
\end{tabular}


Table 1. Continued.

\begin{tabular}{|c|c|c|c|c|c|c|c|}
\hline Case report & Sex & Age & Involved cardiac site & Surgery & Survival & Circumstances and mechanism & Cause of death \\
\hline Parra et al. [54] & male & $81 \mathrm{y}$ & both left and right ventricle, ventricular septum & yes & Yes & accidental, stingray barb & \\
\hline Galante et al. [55] & male & $22 \mathrm{y}$ & left ventricle & yes, hemodynamically stable & Yes & not specified, gunshot wound & \\
\hline Karigyo et al. [56] & male & $40 \mathrm{y}$ & anterior left ventricle, posterior right ventricle & yes & Yes & not specified, firearm projectile & \\
\hline Sochala et al. [57] & male & $25 \mathrm{y}$ & apex of the left ventricle & yes & Yes & not specified, stab wound & \\
\hline Garrido et al. [58] & male & $54 \mathrm{y}$ & right ventricle & yes & Yes & not specified, radial mechanical saw & \\
\hline Praeger et al. [59] & female & e 31 y & anterior right ventricle & yes & Yes & not specified, stab wound & \\
\hline Prokesch et al. [60] & male & $57 \mathrm{y}$ & left ventricle, interventricular sept & yes, hemodynamically stable & Yes & self-inflicted (suicide attempt), nail gun & \\
\hline Ramponi et al. [61] & female & e 61 y & right ventricle & yes, hemodynamically stable & Yes & self-inflicted (suicide attempt), knife & \\
\hline Panicker et al. [62] & male & $70 \mathrm{y}$ & right ventricle, interventricular sept & yes & Yes & accidental, nail gun & \\
\hline ZarainObrador et al. [63] & male & $43 \mathrm{y}$ & right atrium, right ventricle & yes, hemodynamically stable & Yes & not specified, gunshot wound & \\
\hline
\end{tabular}




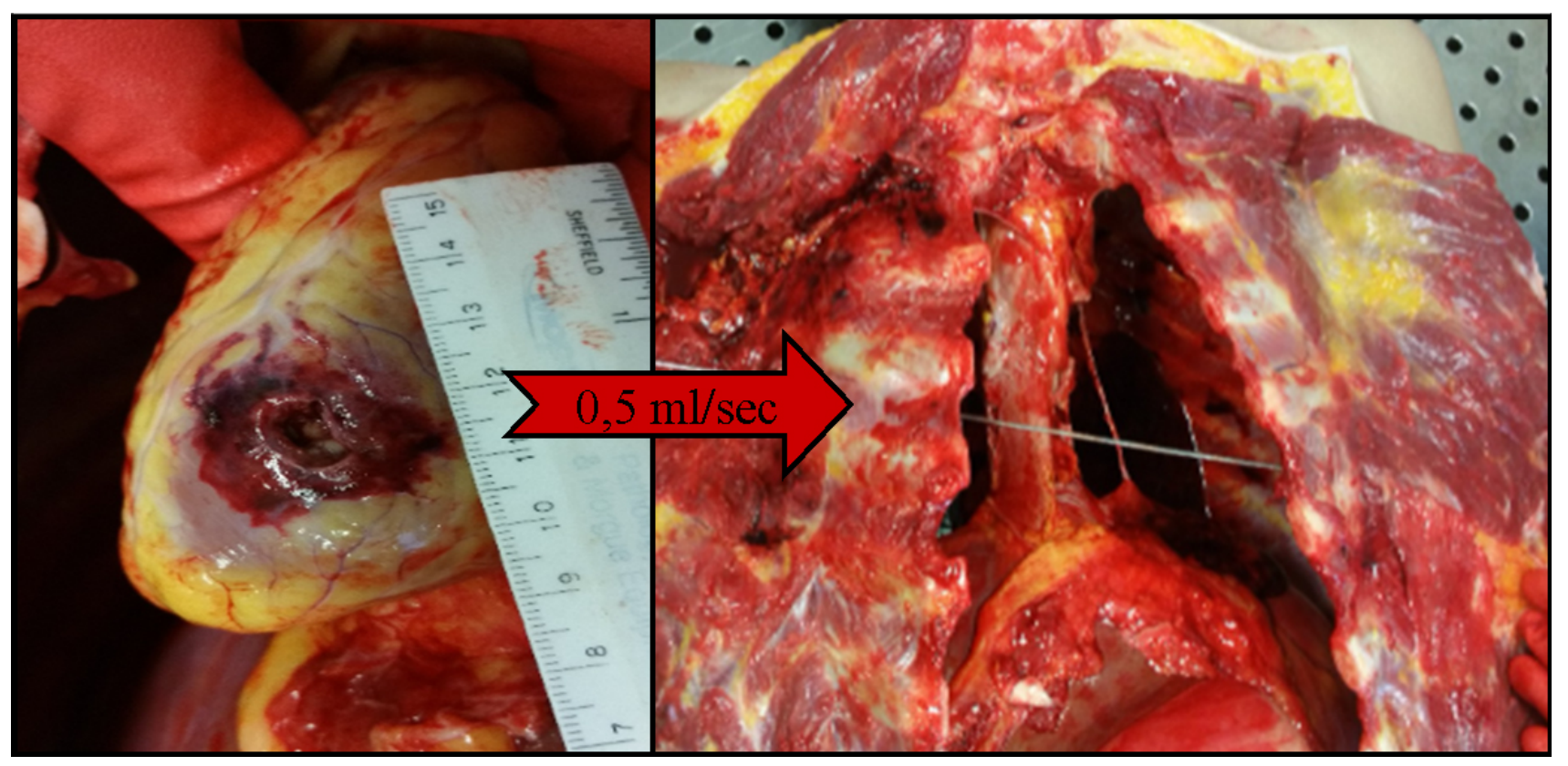

Fig. 1. Intraparenchymal path across the heart, involving the right atrium, the upper portion of the cardiac septum, and the lower portion of the anterolateral side of the left ventricle.

The present study shows that some features of penetrating heart injuries have changed over the past decade. Notably, the mortality rate has decreased, and patient prognosis has improved, likely due to the enhancement of emergency services. Therefore, a careful assessment of the circumstances of death must include a possible failure in the pre-hospital management. The prognosis of patients arriving at the hospital with signs of life in cases of penetrating cardiac wounds is excellent, as described by Kaljusto et al. [68]. The prognosis of nail gun shotwounds patients is better than that of stabbed patients; about half of the patients shot survive if treated promptly. They responded well to cardiac patch and pericardial drainage. Thus, patients with stable hemodynamics and penetrating cardiac wound can survive if treated in the shortest possible time. However, an important limitation of the review presented must be considered: the positive outcome bias, which is inherent in reviews based on series of case reports; to put it another way, linked to the publication of clinical cases based on success stories and not of failed cases.

With the aims to demonstrate that if assistance is provided immediately the chances of survival increased significantly, a concrete case of delayed first aids with death of the patient was examined.

Autopsy findings were:

- a gunshot wound in the middle third of the dorsal side of the right arm $(1 \times 0.9 \mathrm{~cm})$ with an abrasion along its medial edge;

- 3050 cubic centimeters of blood in the right pleural cavity and 3000 cubic centimeters of blood in the left one;

- an oblique, top-to-bottom, and right-to-left intraparenchymal path across the heart, involving the right atrium, the upper portion of the cardiac septum, and the lower portion of the anterolateral side of the left ventricle (Fig. 1);

- death was due to acute hemorrhagic shock caused by a massive bilateral hemothorax.

Through the clinical and autopsy data, the forensic pathologist and the cardiologist established that the patient developed an hemothorax of approximately 0.5 milliliters/seconds (about $50 \%$ of the blood volume) in 1 hour and a half (Table 2).

Table 2. Schematization of rescue times.

\begin{tabular}{lccc}
\hline Timing & History & Delay & VP \\
\hline $23.15-23.30$ & Injury & $0-15^{\prime}$ & Yes \\
23.43 & 1st EMS call & $13^{\prime}$ & Yes \\
00.06 & 2nd EMS call & $23^{\prime}$ & Yes \\
00.16 & Ambulance departure & & Yes \\
00.23 .50 & Ambulance arrival on scene & 39, & Yes \\
00.45 .35 & 1st medical examination & & Yes \\
00.58 .13 & Air ambulance call & & Yes \\
01.15 .45 & Air ambulance arrival on scene & & Yes \\
02.09 & Air ambulance departure & & Yes \\
02.26 & Cardiac arrest & No \\
03.10 & Death & $01.15^{\prime}-01.30$ No \\
\hline \multicolumn{3}{c}{}
\end{tabular}

Analyzing the events, they concluded that the boy could have reached the hospital in about 30-45 minutes in stable hemodynamic conditions with an immediate rescue. Therefore, the boy would have survived with a high probability. 


\section{Conclusions}

The literature review on penetrating cardiac trauma showed a significantly increasing positive outcome in those patients, essentially due to improved pre-hospital management and the development of therapeutic workup.

A multidisciplinary approach is essential for the forensic pathologist, to integrate the clinical data with the evidence deriving from the site inspection, external examination, and autopsy [69].

The survival rates depend on the means of injury, cardiac site involved, the extent of the damage, the persistence of hemodynamic stability.

When patient dies, it is necessary to analyze the rescue management and its consistency with the improvement of diagnostic and therapeutic methods.

The present study confirms the reduction of patient mortality if first aid is rapid, as recommended by the literature, and also that patients with noticeable vital signs, when promptly assisted, had a high probability of positive outcomes.

In conclusion, the conducted study highlight that forensic pathologists must consider every possible scenario, in addition to those typical of traumatic pathology.

\section{Abbreviations}

EMS, emergency medical service; VP, vital parameters.

\section{Author contributions}

LC and BB perform autoptic examination; GB analyzed the literature; MF writing; SDS review and editing; SV language supervision. All authors have read and agreed to the published version of the manuscript.

\section{Ethics approval and consent to participate}

Informed consent were obtained by relatives of the deceased person.

\section{Acknowledgment}

Thanks to all the peer reviewers for their opinions and suggestions.

\section{Funding}

This research received no external funding.

\section{Conflict of interest}

The authors declare no conflict of interest.

\section{References}

[1] Fedakar R, Türkmen N, Durak D, Gündoğmuş UN. Fatal traumatic heart wounds: review of 160 autopsy cases. The Israel Medical Association Journal. 2005; 7: 498-501.

[2] Embrey R. Cardiac Trauma. Thoracic Surgery Clinics. 2007; 17 : 87-93.
[3] O'Connor J, Ditillo M, Scalea T. Penetrating Cardiac Injury. Journal of the Royal Army Medical Corps. 2009; 155: 185-190.

[4] Pereira BMT, Nogueira VB, Calderan TRA, Villaça MP, Petrucci O, Fraga GP. Penetrating cardiac trauma: 20-y experience from a university teaching hospital. The Journal of Surgical Research. 2013; 183: 792-797.

[5] Carr JA, Buterakos R, Bowling WM, Janson L, Kralovich KA, Copeland $\mathrm{C}$, et al. Long-term functional and echocardiographic assessment after penetrating cardiac injury: 5-year follow-up results. The Journal of Trauma. 2011; 70: 701-704.

[6] Connelly TM, Kolcow W, Veerasingam D, DaCosta M. A severe penetrating cardiac injury in the absence of cardiac tamponade. Interactive Cardiovascular and Thoracic Surgery. 2017; 24: $286-287$.

[7] Affronti A, Di Bella I, Di Lazzaro D, Capozzi R, Scarnecchia E, Ragni T. Cardiac tamponade caused by a migrating sewing needle. Journal of Cardiovascular Medicine. 2016; 17: e136e137.

[8] Al-Jalahma J, Al-Hakami W, Musayab Y, Ismail T, Nair R, Thani KB. Penetrating Injury of the Heart from a Chronically Migrating Foreign Body. The Annals of Thoracic Surgery. 2016; 102: e191-e192.

[9] Endlich M, Schiller W, Mellert F, Probst C. Implantation of a total abdominal mesh plastic ending up in multiple, lethal right heart injuries. Interactive CardioVascular and Thoracic Surgery. 2015; 21: 135-136.

[10] Al Shammeri OM, Crowell R, Stewart K, Fort S. Failed pericardiocentesis for acute cardiac tamponade: two cases associated with bivalirudin administration during PCI. Catheterization and Cardiovascular Interventions. 2010; 75: 114-116.

[11] Ali TA, Fatimi SH, Hasan BS. Transcatheter closure of a traumatic ventricular septal defect using an Amplatzer ${ }^{\mathrm{TM}}$ atrial septal occluder device. Catheterization and Cardiovascular Interventions. 2013; 82: 569-573.

[12] Almeida ALCD, Cavalcante VM, Teixeira MDC, Freitas GRCD. Pacemaker electrode misplaced in the left ventricle. Arquivos Brasileiros De Cardiologia. 2010; 95: e83-e87.

[13] Kanchan T, Menezes RG, Sirohi P. Penetrating cardiac injuries in blunt chest wall trauma. Journal of Forensic and Legal Medicine. 2012; 19: 350-351.

[14] Aykan AC, Oguz AE, Yildiz M, Özkan M. Complete atrioventricular block associated with non-penetrating cardiac trauma in a 40-year-old man. The Journal of Emergency Medicine. 2013; 44: e41-e43.

[15] de Bruin G, Pereira da Silva R. Stroke complicating traumatic ventricular septal defect. The Journal of Emergency Medicine. 2012; 43: 987-988.

[16] Burgazli KM, Cetin SM, Atmaca N, Mericliler M, Evagelopoulos N, Daebritz SH. An unusual case of retained bullet in the heart since World War II: a case report. European Review for Medical and Pharmacological Sciences. 2013; 17: 420-421.

[17] Anselmi A, Luciani N, Perri G, Palladino M, Tsiopoulos V. Different clinical pictures of penetrating ulcer of the aorta, an underrated aortic disease. Journal of Cardiovascular Medicine. 2010; 11: 815-819.

[18] Kulaylat AN, Chesnut CH, Patel S, Rocourt DV, Clark JB. Penetrating Cardiac Nail Gun Injury in a Child. Pediatric Emergency Care. 2016; 32: 536-537.

[19] Cottini M, Pergolini A, Ranocchi F, Musumeci F. The Role of Heart Team Approach in Penetrating Cardiac Trauma: Case Report and Review of the Literature. Brazilian Journal of Cardiovascular Surgery. 2018; 33: 99-103.

[20] Diez C, Conti B, McCunn M, Aboutanos MB, Varon AJ. CASE 6-2015: Penetrating Biventricular Cardiac Injury in a Trauma Patient: Heart Versus Machete. Journal of Cardiothoracic and Vascular Anesthesia. 2015; 29: 797-805. 
[21] Grande AM, Antonacci F, Aseni P. Penetrating cardiac stab wounds: A case report with management algorithm and review of the literature. Emergency Care Journal. 2018; 14.

[22] Haghshenas J, Sridhar M, Guerrero M, Yoon J, Zuberi J, Madlinger RV. Nail Gun to the Heart-Patch Repair of Penetrating Cardiac Injury. The American Surgeon. 2019; 85: e249e251.

[23] Leite L, Gonçalves L, Nuno Vieira D. Cardiac injuries caused by trauma: Review and case reports. Journal of Forensic and Legal Medicine. 2017; 52: 30-34.

[24] Kremer H, Wilson J. Penetrating cardiac injury with urgent not emergent thoracotomy. Missouri Medicine. 2010; 107: 328330.

[25] Gatti G, Forti G, Bologna A, Sagrati G, Gustin G, Korcova R, et al. Rescue extracorporeal membrane oxygenation in a young man with a stab wound in the chest. Injury. 2014; 45: 15091511.

[26] Claassen CW, O'connor JV, Gens D, Sikorski R, Scalea TM. Penetrating cardiac injury: think outside the box. The Journal of Trauma. 2010; 68: E71-E73.

[27] Krishna K, Behera C, Singh SR, Bhardwaj DN. Ice pick death: a case report and discussion of the injury pattern. Journal of Forensic and Legal Medicine. 2013; 20: 803-805.

[28] Zhang W, Cao L, Hu S, Huang X, Yang Y. Nail gun penetrating cardiac injury in a young child. The Lancet. 2014; 384: 828.

[29] Hsia RY, Mahadevan SV, Brundage SI. Penetrating cardiac injury from a wooden knitting needle. The Journal of Emergency Medicine. 2012; 43: 116-119.

[30] Peter O, Ubomír M, Ján Š, Roman K, Jozef Š. Fatal suicidal perforating crossbow bolt injury of the chest. Soudni Lekarstvi. 2020; 65: 27-29.

[31] Oliemy A, Mahesh B, Pathi V. Acute Traumatic Right to Left Cardiac Shunt. The Annals of Thoracic Surgery. 2016; 102: e303-e304.

[32] Barbosa FM, Quiroga JM, Otero AE, Girela GA. Aortic valve regurgitation with aorto-right ventricular fistula following penetrating cardiac injury. Interactive CardioVascular and Thoracic Surgery. 2011; 13: 653-654.

[33] Greenlees G, Govewalla P, Haqzad Y, Sharkey A, Cartwright N. Penetration of the Heart by an Airgun Pellet: a Case without Significant Effusion or Valvular Injury. The Annals of Thoracic Surgery. 2019; 108: e9-e10.

[34] Karigyo CJT, Fan OG, Yoshida MM, Menescal RJ, Tarasiewich MJ. Transfixing cardiac injury with perforations in stomach, diaphragm and lung: unusual scenario in penetrating trauma. Revista Brasileira De Cirurgia Cardiovascular. 2014; 29: 103-106.

[35] Pradhan S, Sapkota R, Shrestha UK, Amatya R, Koirala B. Impalement injury to the heart. Kathmandu University Medical Journal. 2011; 9: 80-82.

[36] Yu H, Zhu D, Liang P, Liu B. Successful management of penetrating cardiac injury under guidance of transesophageal echocardiogram. The American Journal of Emergency Medicine. 2010; 28: 986.e5-986.e6.

[37] Enomoto Y, Sudo Y, Sueta T. Traumatic Tricuspid Insufficiency Requiring Valve Repair in an Acute Setting. Hellenic Journal of Cardiology. 2015; 56: 516-519.

[38] Gnassingbé K, Simlawo K, Egbohou P, Noumedem NB, Mama AW, Mihluedo-Agbolan K, et al. Cardiac Injury in Child Managed Successfully in Underprivileged Hospital of Africa. World Journal for Pediatric and Congenital Heart Surgery. 2013; 4: 305-307.

[39] Han FY, Reyes KG, Bleiweis MS. Managing extensive mitral valve and ventricular septal injuries secondary to penetrating trauma. European Journal of Cardio-Thoracic Surgery. 2018; 53: 284-285.

[40] Branch CF, Adams J. Left ventricular rupture with resulting car- diac tamponade due to blast force trauma from gunshot wound. Journal of Emergency Medicine. 2012; 43: 263-265.

[41] Faloye AO, Gershon RY. Traumatic Ventricular Septal Defect after Stab Wound to the Chest Missed by Transthoracic Echocardiography. A \& A Case Reports. 2017; 9: 65-68.

[42] Rupprecht H, Ghidau M. Penetrating Nail-Gun Injury of the Heart Managed by Adenosine-Induced Asystole in the Absence of a Heart-Lung Machine. Texas Heart Institute Journal. 2014; 41: 429-432.

[43] Iş̧1k O, Engin Ç, Daylan A, Şahutoğlu C. Air gun pellet: cardiac penetration and peripheral embolization. Turkish Journal of Trauma \& Emergency Surgery. 2016; 22: 301-303.

[44] Kumar A, Kohli A, Verma SK. Fatal cardiac tamponade by Bodkin. Medicine, Science and the Law. 2013; 53: 93-95.

[45] Chen HM, Chou CJ, Shih MC, Yeh YS. An unusual fatal penetrating coronary artery injury with effective perioperative management. European Journal of Cardio-Thoracic Surgery. 2012; 41: 445-447.

[46] Maffei E, Spaggiari I, Arcadi T, Martini C, Aldrovandi A, Cademartiri F. A bullet wandering through the heart. Journal of Cardiovascular Computed Tomography. 2010; 4: 144-146.

[47] Nwiloh J, Edaigbini S, Danbauchi S, Aminu MB, Oyati A. Arrow injury to the heart. The Annals of Thoracic Surgery. 2009; 90: $287-289$.

[48] Duric Z, Gosev I, Belina D. Penetrating injury to the right side of the heart without hemodynamic compromise. The Journal of Thoracic and Cardiovascular Surgery. 2012; 144: 263-264.

[49] Bartoloni G, Trio F, Bartoloni A, Giorlandino A, Pucci A. A fatal stab wound causing selective injury to the left anterior descending coronary artery, myocardial infarction and delayed cardiac tamponade. Forensic Science International. 2013; 229: e16-e18.

[50] Michalsen KL, Iguidbashian JP, Kyser JP, Long WB. LowVelocity Nail-Gun Injuries to the Interventricular Septum: Report of Two Cases, one in a Child. Texas Heart Institute Journal. 2015; 42: 393-396.

[51] Esfahani SA, Yousefzadeh DK. Pericardial tamponade with a normal cardiopericardial silhouette due to a penetrating metallic projectile propelled by a lawnmower. Pediatric Cardiology. 2013; 34: 2044-2046.

[52] Madani M, Drissi M, Ajaja MR, Rifai M, Moutaouakkil EM, Cheikhaoui Y, et al. Nail gun may cause heart injury: a young adult's misadventure. International Emergency Nursing. 2012; 20: 98-101.

[53] Jodati A, Safaei N, Toufan M, Kazemi B. A unique nail gun injury to the heart with a delayed presentation. Interactive Cardiovascular and Thoracic Surgery. 2011; 13: 363-365.

[54] Parra MW, Costantini EN, Rodas EB, Gonzalez PJ, Salamen OJ, Catino JD, et al. Surviving a transfixing cardiac injury caused by a stingray barb. The Journal of Thoracic and Cardiovascular Surgery. 2010; 139: e115-e116.

[55] Galante J, London JA. Left ventricular bullet embolus: a case report and review of the literature. The Journal of Emergency Medicine. 2010; 39: 25-31.

[56] Karigyo CJT, Fan OG, Rodrigues RJ, Tarasiewich MJ. Transfixing gunshot wound to the heart: case report. Revista Brasileira De Cirurgia Cardiovascular. 2011; 26: 298-300.

[57] Sochala M, Aïssou L, Sorbets E, Pop N, Sleiman C, Goudot F, et al. Delayed cardiac tamponade following management of a massive hemothorax related to a penetrating thoracic trauma. International Journal of Cardiology. 2014; 172: e69-e70.

[58] Garrido JM, Esteban M, López-Checa S. Cardiothoracic trauma with a mechanical saw. Asian Cardiovascular and Thoracic Annals. 2012; 20: 612-612.

[59] Praeger PI, Praeger J, Abdel-Razek AM, Elmann EM. Stab wound of the heart with unusual sequelae. Texas Heart Institute Journal. 2013; 40: 353-357. 
[60] Prokesch BC, Mangino JE. Nail gun attempted suicide and traumatic ventricular perforations. Monthly Journal of the Association of Physicians. 2014; 107: 589.

[61] Ramponi F, Mejia R, Conaglen P, Musicki K, Singh T. Redo sternotomy and cardiopulmonary bypass to repair a right ventricular penetrating injury. Journal of Cardiac Surgery. 2013; 28: 717.

[62] Panicker AT, Nugent K, Mink J, Glaser J, Bradley K, Siric F, et al. Bedside Ultrasonography in the Management of Penetrating Cardiac Injury Caused by a Nail Gun. The Journal of Emergency Medicine. 2019; 56: 197-200.

[63] Zarain Obrador L, Al-Lal YM, de Tomás Palacios J, Amunategui Prats I, Turégano Fuentes F. Transmediastinal and transcardiac gunshot wound with hemodynamic stability. Case Reports in Surgery. 2014; 2014: 985097.

[64] Isaza-Restrepo A, Bolívar-Sáenz DJ, Tarazona-Lara M, Tovar JR. Penetrating cardiac trauma: analysis of 240 cases from a hospital in Bogota, Colombia. World Journal of Emergency Surgery. 2017; 12: 26.
[65] Morse BC, Mina MJ, Carr JS, Jhunjhunwala R, Dente CJ, Zink $\mathrm{JU}$, et al. Penetrating cardiac injuries: a 36-year perspective at an urban, Level i trauma center. The Journal of Trauma and Acute Care Surgery. 2016; 81: 623-631.

[66] Altun G, Altun A, Yilmaz A. Hemopericardium-related fatalities: a 10-year medicolegal autopsy experience. Cardiology. 2005; 104: 133-137.

[67] Lateef Wani M, Ahangar AG, Wani SN, Irshad I, Ul-Hassan N. Penetrating cardiac injury: a review. Trauma Monthly. 2012; 17: 230-232.

[68] Kaljusto M, Skaga NO, Pillgram-Larsen J, Tønnessen T. Survival predictor for penetrating cardiac injury; a 10-year consecutive cohort from a scandinavian trauma center. Scandinavian Journal of Trauma, Resuscitation and Emergency Medicine. 2015; 23: 41 .

[69] Ferrara M, Sessa F, Rendine M, Spagnolo L, De Simone S, Riezzo I, et al. A multidisciplinary approach is mandatory to solve complex crimes: A case report. Egyptian Journal of Forensic Sciences. 2019; 9. 